\title{
Competitive strategy trends among the Malaysian wooden furniture industry: An strategic groups analysis.
}

\begin{abstract}
The competitiveness indexes of the Malaysian furniture industry are declining regardless of the strong growth of the over two last decades. Although there are nominated factors to analyze this conflict from resource based view, other factors from competitive strategy view should be considered to attain a comprehensive image of the industry's structure in the current situation. This study developed a strategic group analysis based on Porter's competitive business level strategy to examine the industry structure and its likely association with the current situation of the industry as well strategic trends in the future. The obtained results demonstrated that: There are at least four logical strategic groups in the industry. Major groups that form main body of the industry do not pursue a distinctive competitive strategic orientation and so the industry is placed in a fragile position in terms of the competitive strategy. The industry is significantly under force from intensive competition and bargaining power of buyers. Differentiation is the most efficient and Cost leadership is the least efficient strategy in the industry. The industry significantly attempts to develop its strategic activities toward distinct strategic orientations in general and differentiation more than two other competitive strategic orientations. Hence, moving from dispassionate groups toward differentiation group will be main strategic effort in the future of the industry.
\end{abstract}

Keyword: Furniture industry; Strategic groups; Competitive strategy; Competitive forces; Wood products. 